\title{
Signal Transduction Profiling of Angiotensin II Type 1 Receptor With Mutations Associated to Atrial Fibrillation in Humans
}

\author{
Sarah C. Simões ${ }^{1 * t}$, André L. Balico-Silva ${ }^{1 \dagger}$, Lucas T. Parreiras-e-Silva ${ }^{1}$, \\ André L. B. Bitencourt ${ }^{1}$, Michel Bouvier ${ }^{2}$ and Claudio M. Costa-Neto ${ }^{1 *}$ \\ ${ }^{1}$ Ribeirao Preto Medical School, Department of Biochemistry and Immunology, University of São Paulo, Ribeirao Preto, Brazil, \\ ${ }^{2}$ Department of Biochemistry and Molecular Medicine and Institute for Research in Immunology and Cancer, University of \\ Montréal, Montréal, QC, Canada
}

\section{OPEN ACCESS}

Edited by:

Vsevolod V. Gurevich,

Vanderbilt University, United States

Reviewed by:

Federico Mayor,

Autonomous University of Madrid,

Spain

Pascale Crepieux,

Centre National de la Recherche Scientifique (CNRS), France

*Correspondence:

Sarah C. Simões

sarah_capelupe@hotmail.com

Claudio M. Costa-Neto

claudio@fmrp.usp.br

${ }^{\dagger}$ These authors have contributed equally to this work

Specialty section:

This article was submitted to Experimental Pharmacology and

Drug Discovery,

a section of the journal

Frontiers in Pharmacology

Received: 28 August 2020 Accepted: 18 November 2020 Published: 22 December 2020

Citation:

Simões SC, Balico-Silva AL, Parreiras-e-Silva $L T$, Bitencourt $A L B$, Bouvier M and Costa-Neto CM (2020)

Signal Transduction Profiling of Angiotensin II Type 1 Receptor With

Mutations Associated to Atrial

Fibrillation in Humans.

Front. Pharmacol. 11:600132. doi: 10.3389/fphar.2020.600132
The AT1 receptor (AT1R) has a major role in the Renin-Angiotensin System, being involved in several physiological events including blood pressure control and electrolyte balance. The AT1R is a member of the $G$ protein coupled receptors (GPCR) family, classically known to couple $G_{\alpha q}$ and engage $\beta$-arrestin recruitment. Both $G$ protein and arrestin signaling pathways are involved in modulation of different downstream kinases. A previous study reported that mutations in the AT1R (A244S and I103T-A244S) were positively correlated with higher risk of atrial fibrillation in men. Based on that report, we aimed to investigate if these mutations, including 1103T only, could affect AT1R signal transduction profile, and consequently, implicate in atrial fibrillation outcome. To address that, we engineered an AT1R carrying the above-mentioned mutations, and functionally evaluated different signaling pathways. Phosphokinase profiler array to assess the mutations downstream effects on kinases and kinase substrates phosphorylation levels was used. Our results show that the 1103T-A244S mutant receptor presents decreased $\beta$-arrestin 2 recruitment, which could lead to a harmful condition of sustained $G_{\alpha q}$ signaling. Moreover, the phosphokinase profiler array revealed that the same mutation led to downstream modulation of kinase pathways that are linked to physiological responses such as fibrous tissue formation, apoptosis and cell proliferation.

Keywords: Angiotensin II receptor, Angll, AT1 receptor, signalling, cardiovascular diseases, mutations

\section{INTRODUCTION}

G protein coupled receptors (GPCRs) represent the major family of cell surface receptors (Wise et al., 2004). It is estimated that about $40 \%$ of the marketed drugs have GPCRs as targets (Rask-Andersen et al., 2011; Hauser et al., 2017). The angiotensin II type 1 receptor (AT1R), a G protein coupled receptor, is the main receptor of the Renin-Angiotensin System, and angiotensin II (AngII) is the main agonist of this system. Along with the AT1R, AngII plays a direct role in the control of blood pressure, aldosterone release, electrolyte balance, and other physiological events (Fyhrquist and Saijonmaa, 2008). In addition, AT1R activation also promotes cell proliferation, inflammation and fibrosis (Forrester et al., 2018), which are related to cardiovascular diseases (de Gasparo et al., 2000). Activation of AT1R by AngII triggers the canonical $G_{\alpha q}$ protein signaling pathways, which leads to 
inositol trisphosphate $\left(\mathrm{IP}_{3}\right)$ and diacylglycerol (DAG) generation, and $\mathrm{Ca}^{2+}$ mobilization from the endoplasmic reticulum, culminating in protein kinase $\mathrm{C}(\mathrm{PKC})$ and other downstream kinases activation, including ERK1/2. In addition, after AT1R activation by AngII, G protein coupled receptor kinases (GRKs) promote the phosphorylation of the receptor and $\beta$-arrestins recruitment, leading to receptor internalization and activation of other signaling pathways (Lima et al., 2014).

Anomalies in GPCRs caused by polymorphisms are associated with a variety of phenotypes and predisposition to certain diseases. It has been described more than 700 mutations that inactivate or over activate receptors, which are related to over 30 different human diseases (Schöneberg et al., 2004; Zalewska et al., 2014; Fukami et al., 2018). Marott, Nordestgaard et al. (2013) identified genetic variants of the AT1R in patients with atrial fibrillation (AF). The mutations A244S and I103T-A244S (Figure 1A) occur in conserved residues in mammals and were correlated with $\mathrm{AF}$ predisposition in men. It was reported that the risk of development of AF in heterozygotes for the variants A244S and I103T-A244S is higher when compared to individuals that do not carry these variants. It was then hypothesized that such mutations could possibly affect receptor responses, leading to an increase of inflammation, fibrosis, expression of gap junctions and ion channels, which could be related to the structural and electrical remodeling of the myocardial atrium (Marott et al., 2013).

Based on that, in this study we wanted to understand whether the A244S and I103T-A244S variants in the AT1R would affect the receptor signaling regarding its downstream pathway. We generated the A244S and I103T-A244S mutations in the human AT1R and characterized their impact in AngII affinity and signal transduction. We also evaluated the effects of the I103T mutant alone, which although not found and reported in the previous study, it was important here to allow comprehensive structure/function analyses in regard to the contributions of the mutation to the AT1R signaling profile and possible physiological effects.

\section{MATERIALS AND METHODS}

\section{Receptor Mutagenesis}

The site-direct mutations in AT1 receptor: I103T, A244S and I103T-A244S were generated by whole plasmid PCR technique using oligonucleotide primers containing the A244S mutation (5'-GGCAATTACCTATGTAAGACTGCT TCAGCCAGCGT $3{ }^{\prime} / 5^{\prime}$-ACGCTGGCTGAAGCAGTCTTA CATAGGTAATT- $\left.3^{\prime}\right)$ and the I103T mutation $\left(5^{\prime}\right.$-TTTAAG ATAATTATGTCAATTGTGCTTTTCTTT- $3^{\prime} / 5^{\prime}$-TTTAAG ATAATTATGTCAATTGTGCT TTTCTTT- $3^{\prime}$ ). Extension was performed using a high-fidelity DNA polymerase (Taq HiFi; Invitrogen). DpnI endonuclease (Invitrogen) was used to digest the parental DNA template. The mutants were sequenced with the Big Dye ${ }^{\mathrm{TM}}$ Terminator v3.1 Cycle Sequencing Ready Reaction Kit (Perkin Elmer) according to the manufacture's instruction.

\section{Cell Culture and Transfections}

HEK293T cells were cultivated in Dulbecco's Modified Eagle Medium from ThermoFisher Scientific company (DMEM) supplemented with $10 \%$ of fetal bovine serum (Vitrocell), 1 $\mathrm{U} / \mathrm{ml}$ penicillin/streptomycin and incubated at $37^{\circ} \mathrm{C}$ in a $5 \%$ $\mathrm{CO}_{2}$ environment. Expression plasmids containing wild type (WT), mutated AT1 receptors and BRET-based biosensors were transiently transfected into cells using polyethylenimine (PEI $25 \mathrm{kDa}$ linear; Polyscience) at a ratio of 3:1 PEI/DNA. The proportions of DNA of WT AT1R were adjusted according to a previous analysis of the expression level (see Supplementary Figure S1). When necessary, total DNA amount was adjusted with salmon sperm DNA (Invitrogen). Assays were performed $48 \mathrm{~h}$ after cell transfection.

\section{Competition Binding}

HEK293T cells $\left(3 \times 10^{5}\right.$ cells/well $)$ transiently expressing the receptors were transferred to 24 -well culture plates $24 \mathrm{~h}$ after the transfection. One day after plating, cells were washed once in cold buffer ( $25 \mathrm{mM}$ Tris- $\mathrm{HCl}$ buffer, $\mathrm{pH} 7.4$, containing $140 \mathrm{mM}$ $\mathrm{NaCl}, 5 \mathrm{mM} \mathrm{MgCl} 2$ and $0.1 \%$ bovine serum albumin). Cells were incubated with a final concentration of $0.5 \mathrm{nM}\left[{ }^{3} \mathrm{H}\right]-$ angiotensin II and increasing concentrations of angiotensin II, as a competitor, in binding buffer $(25 \mathrm{mM}$ Tris- $\mathrm{HCl}, \mathrm{pH} 7.4$, including $5 \mathrm{mM} \mathrm{MgCl} 2,0.1 \%$ bovine serum albumin and $100 \mu \mathrm{g} /$ $\mathrm{ml}$ bacitracin). Cells were maintained at $4^{\circ} \mathrm{C}$ for at least $16 \mathrm{~h}$, washed twice and then lyzed with lysis buffer (48\% urea, $2 \%$ Nonidet P-40, acetic acid 3M). Cell lysates were transferred to scintillation vials and $3 \mathrm{ml}$ of scintillation liquid (UltimaGold ${ }^{\mathrm{TM}}$ XR; PerkinElmer) were added. Bound radioactivity was quantified on a Tri-Carb 20100 TR liquid scintillation counter (PerkinElmer).

\section{Intracellular $\mathrm{Ca}^{2+}$ Mobilization}

Twenty-four hours after transfection, HEK293T cells transiently expressing the receptors were transferred to 96-well culture plates (ViewPlate-96; PerkinElmer), in a density of $5 \times 10^{4}$ per well with $50 \mu$ of DMEM without phenol supplemented with $10 \%$ FBS and $1 \mathrm{U} / \mathrm{ml}$ penicillin/streptomycin. The cells were incubated after $48 \mathrm{~h}$ at $37^{\circ} \mathrm{C}$ with $50 \mu \mathrm{l}$ of fluorescent dye indicator (FLIPR ${ }^{\oplus}$ Calcium 5 Assay Kit; Molecular Devices) containing probenecid (Sigma), which can prevent the extrusion of the dye. FlexStation 3 Multi-Mode Microplate Reader (Molecular Devices) was used for the measurement of the emission at $525 \mathrm{~nm}$ after the excitation at $485 \mathrm{~nm}$, after the injection of $25 \mu \mathrm{l}$ of the agonist.

\section{$\beta$-arrestin 2 Recruitment}

HEK293T cells $\left(4 \times 10^{4} /\right.$ well $)$ transiently transfected with mutant receptors (1 $\mu \mathrm{g}$ ) or WT AT1R (500 ng), $\beta$ arrestin2-RlucII (25 ng), rGFP-CaaxBox $(400 \mathrm{ng})$ and salmon sperm to complete $2 \mu \mathrm{g}$ of total DNA, were seeded in white opaque 96-well microplates (OptiPlate; PerkinElmer). Forty-eight hours after transfection, bioluminescence resonance energy transfer 2 (BRET2) was monitored in a VictorX Light Luminescence Microplate Reader (PerkinElmer) equipped with different donor/acceptor emission filter sets after 15 min of AngII addition, and 5 min after 
A
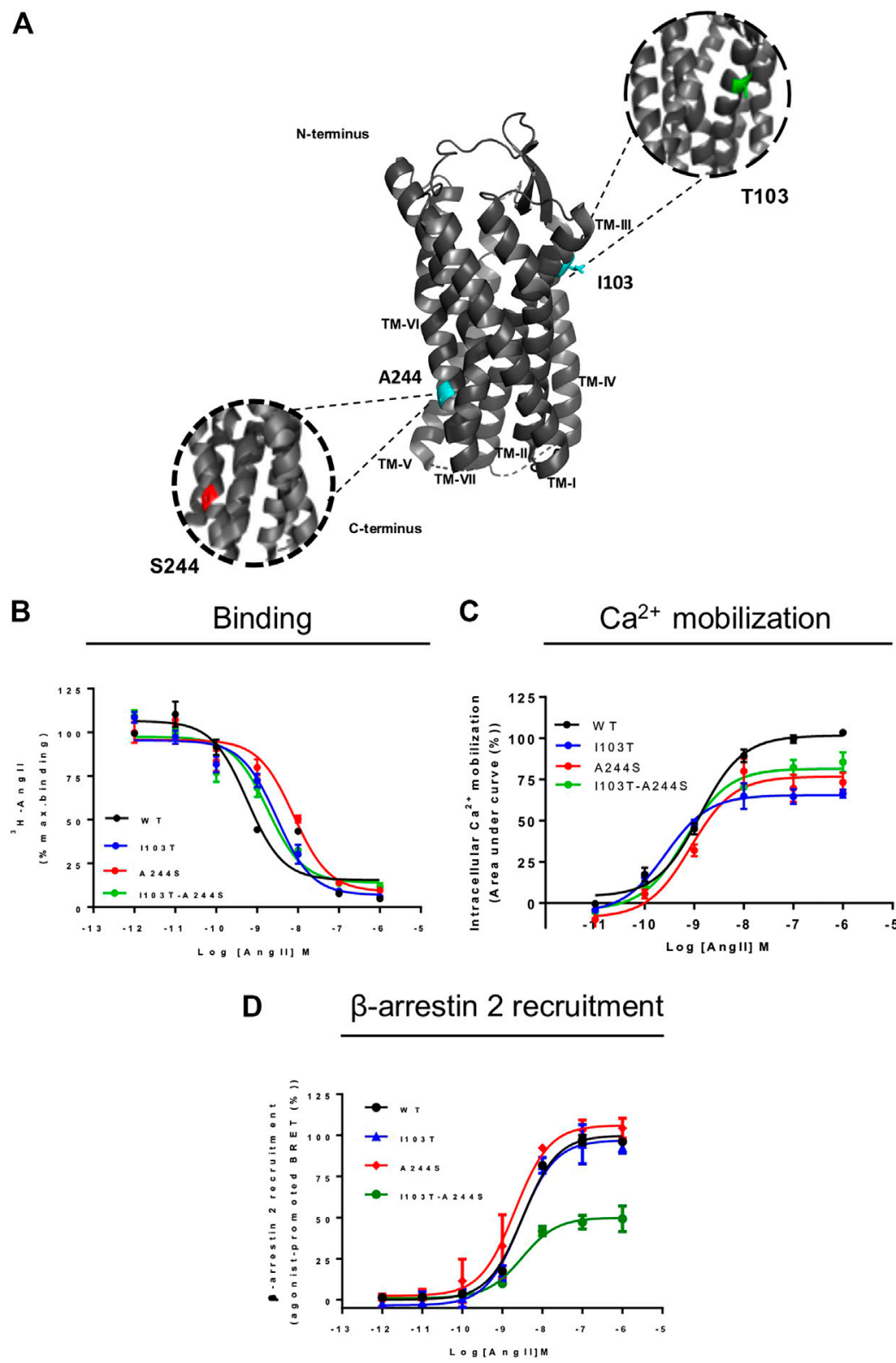

FIGURE 1 | Position of the mutations correlated with atrial fibrillation and comparative analyses of signal profile between AT1 and mutant receptors. (A) Schematic representation of position of mutations in AT1 receptor. TM, transmembrane; cyan, original amino acids residues, Isoleucine and Alanine; green, Threonine substitution; red, Serine substitution. (B) Competition binding profiles for Angll against [ $\left.{ }^{3} \mathrm{H}\right]$-Angll in HEK293T cells transiently expressing the AT1R and mutants. Data are expressed as percentages of the maximum specific binding of the radioligand. (C) Dose-response curve of the $\mathrm{Ca}^{2+}$ mobilization assay after Angll stimulation. Data are expressed as percentages of the maximum $\mathrm{Ca}^{2+}$ mobilization promoted by AT1R. (D) BRET assays showed that in the presence of Angll, AT1R and mutants promote $\beta$-arrestin 2 recruitment. Data are expressed as percentages related to the maximal recruitment promoted the AT1R. All data were generated from at least three independent experiments.

$2.5 \mathrm{mM}$ of coelenterazine 400 -a addition (Biotium) to the cells. BRET2 signals were derived from the ratio between the emission detected with the energy acceptor filter $(515 \pm 20 \mathrm{~nm})$ and the emission detected using the energy donor filter $(400 \pm 70 \mathrm{~nm})$. ßarrestin2-RlucII and rGFP-CaaX expression plasmids were generated at the laboratory of Dr. Michel Bouvier at the University of Montreal, Canada (Parreiras-E-Silva et al., 2017; Namkung et al., 2018).

\section{Phospho-Kinase Profiler Array}

The Human Phospho-Kinase Antibody Array (R\&D Systems) was used as described previously (Santos et al., 2015). Briefly, HEK293T cells $\left(6 \times 10^{6}\right.$ cells/well $)$ were seeded on $10 \mathrm{~cm}^{2}$ culture plates and transfected with the WT receptor $(2.5 \mu \mathrm{g})$, mutant receptors $(5 \mu \mathrm{g})$, and salmon sperm to complete a total DNA amount of $10 \mu \mathrm{g}$. After $24 \mathrm{~h}$, cells were serum starved for $16 \mathrm{~h}$ and then stimulated at $37^{\circ} \mathrm{C}$ 
with $100 \mathrm{nM}$ of AngII as the final concentration for $10 \mathrm{~min}$. Cells were rinsed, lyzed, and the homogenate was clarified by centrifugation at $14,000 \times \mathrm{g}$ for $5 \mathrm{~min}$ at $4^{\circ} \mathrm{C}$. A sample of $300 \mu \mathrm{g}$ of total protein from the lysates was then incubated with the pre-blotted membrane array. After the incubation period, $\mathrm{ECL}^{\mathrm{TM}}$ prime (GE Healthcare) was added and the chemiluminescent signal was captured by ImageQuant 350 (GE Healthcare). For phosphorylation levels analysis, membranes were scanned, and blots were quantified using Image J software. The intensities of the spots were quantified and divided by the values obtained for the WT AT1R (see Supplementary Figure S2; Supplementary Table S1). Substrate's phosphorylation levels were considered differentially modulated when values reached $30 \%$ above or below, as compared with the values obtained for the WT AT1R.

\section{ERK1/2 Phosphorylation}

Twenty-four hours after transfection, $3 \times 10^{5}$ cells were seeded on 6-well plates in DMEM supplemented with $10 \%$ fetal bovine serum, $1 \mathrm{U} / \mathrm{ml}$ penicillin/streptomycin, in a $37^{\circ} \mathrm{C}$ and $5 \% \mathrm{CO}_{2}$ environment. After $24 \mathrm{~h}$, cells were serum starved for $16 \mathrm{~h}$ and then stimulated with $100 \mathrm{nM}$ AngII as the final concentration for $5,10,15,20,25$ or $30 \mathrm{~min}$ at $37^{\circ} \mathrm{C}$, and analyzed for ERK phosphorylation. Cells were lyzed with cold lysis buffer (Tris- $\mathrm{HCl} 10 \mathrm{mM}, \mathrm{pH} 7.5, \mathrm{NaCl} 150 \mathrm{mM}$, EDTA $1 \mathrm{mM}$, EGTA $1 \mathrm{mM}$, SDS $0.1 \%$, Nonidet P-40 1\%, SIGMAFAST $^{\mathrm{TM}}$ protease inhibitor cocktail, sodium orthovanadate $1 \mathrm{mM}$ and sodium fluoride $10 \mathrm{mM}$ ). Following homogenization during $30 \mathrm{~min}$ at $4^{\circ} \mathrm{C}$, cell lysate was centrifuged for $15 \mathrm{~min}$ at $4^{\circ} \mathrm{C}$ and $13,000 \mathrm{rpm}$. Total protein was quantified using Bradford protein assay. Subsequently, $60 \mu \mathrm{g}$ of total protein were separated in SDS-PAGE 12\%, transferred to nitrocellulose membrane and western blotting was performed against total ERK2 and phosphorylated ERK1/2 (both antibodies from Santa Cruz Biotechnology catalog number: sc-1647 and cs377400 respectively). Densitometry of the bands were analyzed using ImageJ program (http://rsb.info.nhi.gov/ij/) and the ratio phosphorylated ERK/total ERK was used to access ERK1/2 activation. Corresponding results were plotted using GraphPad Prism 7 software as the percentage of the maximum ratio values (GraphPad).

\section{Statistical Analyses}

Data are expressed as mean \pm standard error of the mean (S.E.M.) from at least three independent experiments. Sigmoid curves from concentration-response experiments were analyzed using nonlinear curve fitting. Binding, $\mathrm{Ca}^{2+}$ mobilization and $\beta$-arrestin 2 recruitment data were analyzed by one-way Analysis of Variance (ANOVA). When appropriate, Dunnett's post hoc test was used. Significance level was set at $p<$ 0.05. Statistical analyses were carried out using GraphPad Prism 7 (GraphPad) software and are indicated in the legends of the figures.

\section{RESULTS}

\section{Evaluation of Angll Affinity by the Mutant Receptors}

AngII affinities for the mutant receptors were assessed by competition binding assay using radiolabeled ${ }^{3} \mathrm{H}$-AngII, and non-radioactive AngII in different concentrations as the competitor ligand. Considering that the receptors containing the mutations I103T or A244S, as well as the combination of both mutations, are 50\% less expressed in relation to the WT receptor, the transfection levels were adjusted for all assays (see Supplementary Figure S1). As it can be seen in Figure 1B, the competition binding profiles revealed that AngII, in general, has a slightly lower affinity for the mutant receptors, as compared with the WT receptor. Table 1 describes the obtained affinities for AngII in the mutant and WT receptors. It is noteworthy to observe that the A244S mutation caused a 10-fold decrease in AngII affinity, and that the insertion of the second mutation (i.e. generation of the double mutant I103T-A244S) resulted in the recovery of the high affinity profile and the partial recovery of the receptor's capacity to lead to calcium mobilization.

\section{Analysis of Mutant Receptors' Signaling Transduction Pathways}

We evaluated whether the different mutations could affect $\mathrm{Ca}^{2+}$ mobilization and $\beta$-arrestin 2 recruitment after AngII stimulation, two well-known signaling pathways for the AT1R (Chang et al., 1992; Wu et al., 1992). The results show that in $\mathrm{Ca}^{2+}$ mobilization assays all mutant receptors yielded potencies similar to the WT AT1R, and moderate lower efficacies (Figure 1C). Concerning $\beta$-arrestin 2 recruitment, the I103T-A244S mutation yielded a profound decrease in the translocation of $\beta$-arrestin 2 to membrane (reduction of $\sim 50 \%$ ), while the I103T and A244S mutants presented profiles similar to the WT AT1R (Figure 1D).

\section{Profiling of Kinases Pathways Modulated by Mutant Receptors}

The phosphorylation patterns of different kinase substrates were analyzed from lysates of AngII-stimulated HEK293T cells transfected with each of the mutant receptors or the WT AT1R. The membrane blots were quantified and values plotted as a heat-map (Figures 2A; Supplementary Figure S2). Values of modulation fold can be found in Table 2 (see also Supplementary Table S1 for a list of all kinase substrates included in the array and their modulation fold).

We identified 18 kinases and kinases substrates which phosphorylation levels were modulated more than $30 \%$, by at least one of the three mutant receptors, when compared to WT receptor. The A244S mutant receptor led to increased phosphorylation levels of kinases such as ERK1/2, c-Jun and p70 S6 kinase. For the I103T mutant, ERK1/2 MAP kinases showed an increased phosphorylation. The activation of the I103T-A244S double mutant resulted in the decreased phosphorylation levels of cyclic AMP response element 
TABLE 1 | Binding affinity, potency and relative efficacy $\left(E_{\max }\right)$ of Angll to promote $\mathrm{Ca}^{2+}$ mobilization and $\beta$-arrestin 2 recruitment.

\begin{tabular}{|c|c|c|c|c|c|c|c|c|c|}
\hline \multirow[t]{2}{*}{ Receptor } & \multicolumn{3}{|c|}{ Binding } & \multicolumn{3}{|c|}{$\mathrm{Ca}^{2+}$ Mobilization } & \multicolumn{3}{|c|}{$\beta$-arrestin 2 recruitment } \\
\hline & $p \mathrm{C}_{50}$ & $n$ & $\begin{array}{c}K_{d} \\
(n M)\end{array}$ & $p \mathrm{EC}_{50}$ & $n$ & $\begin{array}{c}E_{\max } \\
(\% \text { WT) }\end{array}$ & $p \mathrm{EC}_{50}$ & $n$ & $\begin{array}{c}E_{\max } \\
(\% \text { WT) }\end{array}$ \\
\hline WT & $9.00 \pm 0.17$ & 3 & $0.63 \pm 0.51$ & $8.89 \pm 0.08$ & 5 & 100 & $8.49 \pm 0.05$ & 3 & 100 \\
\hline I103T & $8.63 \pm 0.19$ & 3 & $1.18 \pm 0.94$ & $9.57 \pm 0.13^{*}$ & 3 & $65 \pm 4$ & $8.54 \pm 0.08$ & 3 & $97 \pm 2$ \\
\hline A244S & $8.19 \pm 0.12^{\star}$ & 3 & $6.33 \pm 2.0$ & $9.07 \pm 0.17$ & 5 & $85 \pm 15$ & $8.68 \pm 0.10$ & 3 & $106 \pm 2$ \\
\hline I103T-A244S & $8.61 \pm 0.10$ & 3 & $2.15 \pm 0.67$ & $9.17 \pm 0.09$ & 3 & $81 \pm 5$ & $8.50 \pm 0.10$ & 3 & $50 \pm 4$ \\
\hline
\end{tabular}

HEK293T expressing AT1R/mutant receptors were stimulated with various concentrations of Angll. Ang II binding affinities were obtained from [ ${ }^{3} \mathrm{H}$ ]-Angll competition binding assay. Ca ${ }^{2+}$ mobilization and BRET were normalized to the maximal response of WT (\% $E_{\max }$ of WT) and then averaged. $p E C_{50}$ and $E_{\text {max }}$ were obtained from the nonlinear regression curve of the averaged data. Data represents the means \pm SEM of three or more independent experiments. * $p<0.05$ compared to the WT receptor.

A

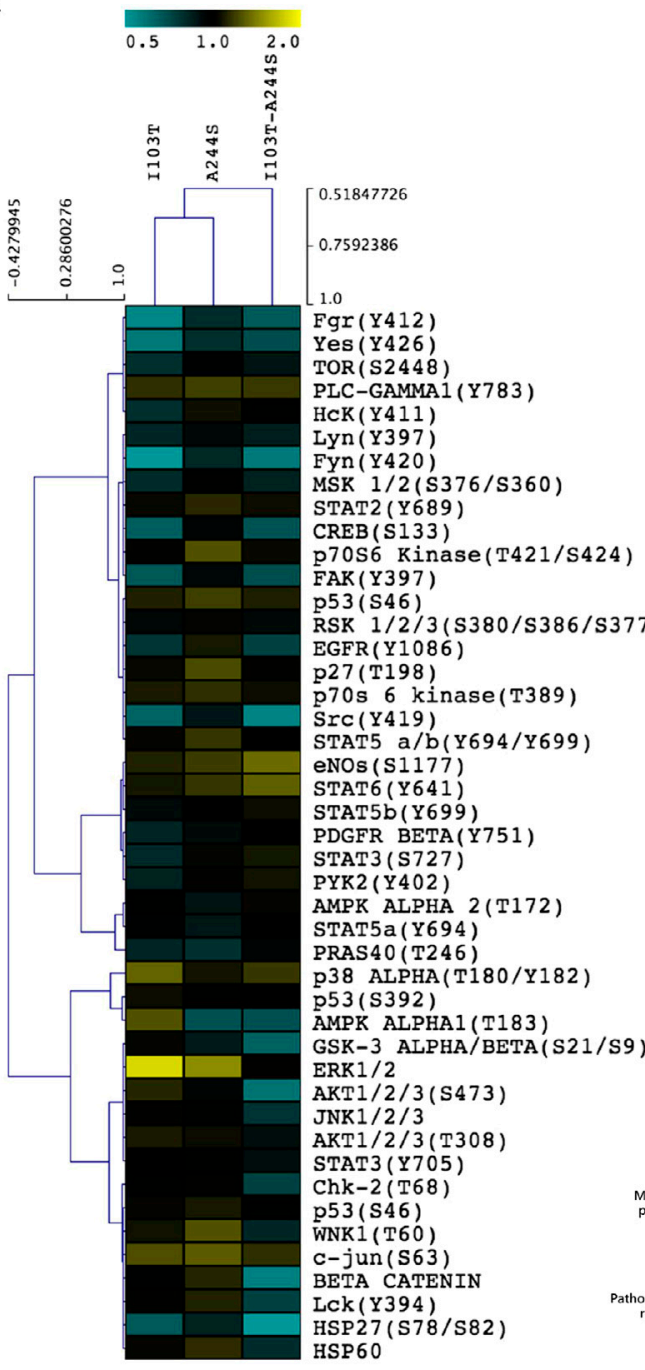

B

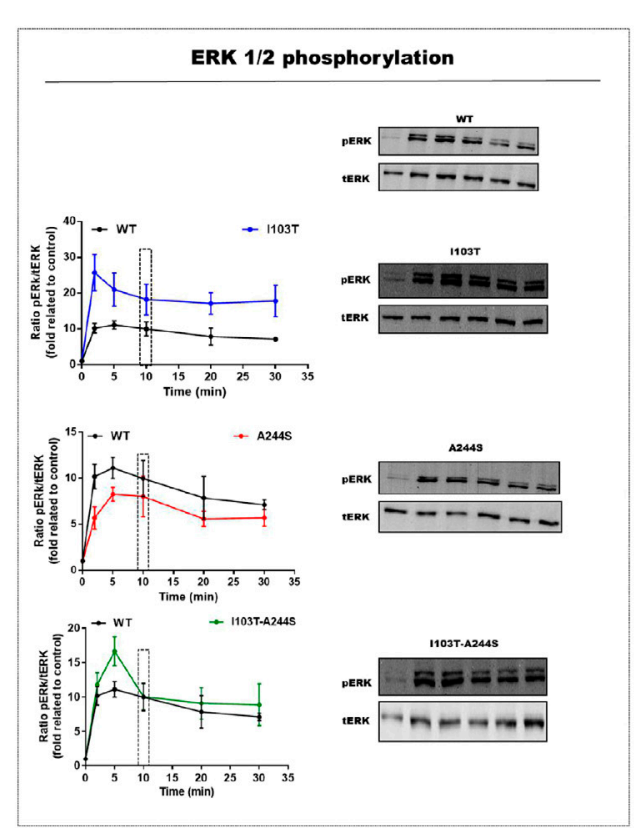

C
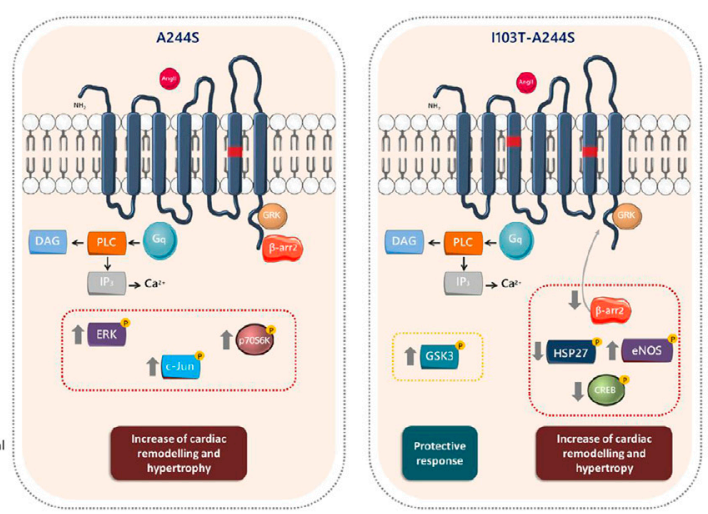

FIGURE 2 Modulation profile of kinases after stimulation of the receptors with the endogenous agonist and signaling pathways affected by the A244S and I103TA244S mutants. (A) HEK293T cells transiently expressing the AT1R and mutant receptors were incubated with $100 \mathrm{nM}$ of Angll for 10 min. The heatmap was generated using the ratio between spots quantified in mutant receptors membrane/spots quantified in WT membrane. (B) Kinetics of ERK1/2 phosphorylation after stimulation with 100 nM Angll (at least 3 independent experiments). (C) Gaq and $\beta$-arrestin interaction with AT1 mutant receptors is shown, and the kinases that were up- or downregulated, as well as the alteration in $\beta$-arrestin 2 recruitment, are highlighted. The physiological consequences due to the modulation of each cluster of proteins are indicated. Up arrows indicate up-modulation, and down arrows represent down-modulation. 
TABLE 2 | Kinases modulated by the mutant receptors in comparison to the WT after 10 min of stimulus with Angll.

\begin{tabular}{|c|c|c|c|}
\hline \multirow[t]{2}{*}{ Modulated proteins } & \multicolumn{3}{|c|}{$\begin{array}{l}\text { Fold change (spots quantified in mutant } \\
\text { receptor membrane/spots quantified in WT } \\
\text { membrane) }\end{array}$} \\
\hline & I103T & A244S & I103T-A244S \\
\hline p38a & $1.39 \boldsymbol{\Delta}$ & 1.10 & 1.23 \\
\hline ERK1/2 & $1.85 \boldsymbol{\Delta}$ & $1.55 \boldsymbol{\Delta}$ & 1.03 \\
\hline GSK-3 $\alpha / \beta$ & 1.05 & 0.90 & $0.67 \boldsymbol{\nabla}$ \\
\hline AMPKa1 & $1.32 \boldsymbol{\Delta}$ & 0.73 & 0.73 \\
\hline AKT1/2/3 (S473) & 1.17 & 0.96 & $0.62 \nabla$ \\
\hline CREB & $0.69 \nabla$ & 0.97 & $0.70 \nabla$ \\
\hline HSP27 & $0.70 \nabla$ & 0.87 & $0.46 \nabla$ \\
\hline$\beta$-Catenin & 0.98 & 1.17 & $0.58 \nabla$ \\
\hline c-jun & $1.31 \boldsymbol{\Delta}$ & $1.37 \boldsymbol{\Delta}$ & 1.20 \\
\hline Src & $0.67 \boldsymbol{\nabla}$ & 0.90 & $0.57 \boldsymbol{\nabla}$ \\
\hline p70 S6 kinase & 1.03 & $1.32 \boldsymbol{\Delta}$ & 1.06 \\
\hline eNOs & 1.16 & 1.24 & $1.42 \boldsymbol{\Delta}$ \\
\hline Fyn & $0.48 \boldsymbol{\nabla}$ & 0.85 & $0.60 \nabla$ \\
\hline Yes & $0.60 \boldsymbol{\nabla}$ & 0.84 & 0.74 \\
\hline Fgr & $0.56 \nabla$ & 0.84 & $0.70 \nabla$ \\
\hline STAT6 & 1.11 & 1.22 & $1.37 \boldsymbol{\Delta}$ \\
\hline p27 & 1.06 & $1.30 \boldsymbol{\Delta}$ & 1.03 \\
\hline WNK1 & 1.10 & $1.33 \boldsymbol{\Delta}$ & 0.86 \\
\hline
\end{tabular}

HEK293T protein cell lysates expressing wild-type AT1R or mutant receptors were stimulated with Ang II and incubated with the phosphokinase array membranes. Results were plotted using the ratio between spots quantified in mutant receptors membrane/ spots quantified in WT receptor membrane. Only kinases or substrates with intensity changes of $\pm 30 \%$ were considered to be affected by the condition (indicated by a black triangle. $\mathbf{\Delta}$ : up-modulation $\mathbf{\nabla}$ : down-modulation).

binding protein (CREB) and of glycogen synthase kinase- $3 \alpha / \beta$ $(\mathrm{GSK} 3 \alpha / \beta)$, but also led to the elevation of endothelial nitric oxide synthase (eNOS) phosphorylation levels. The HSP27 presented a lower phosphorylation profile for all the mutant receptors, but it was more pronounced for the I103T-A244S mutant.

\section{Analysis ERK1/2 Phosphorylation Kinetics}

The ERK1/2 MA P kinase activation was also assessed by western blot after AngII stimulation for different times (Figure 2B). We found that the I103T mutation led to 3-fold increased ERK1/2 phosphorylation levels, while both A244S and I103T-A244S mutants presented phosphorylation profiles similar to the WT AT1R. The peak of ERK $1 / 2$ activation at $5 \mathrm{~min}$ is 1.5 -fold higher after I103T-A244S mutant stimulation as compared to the WT receptor. These results corroborate the modulation levels observed in the phospho-kinases activation profile (see Figure 2A).

\section{DISCUSSION}

The AT1R is directly involved in the establishment and progression of cardiovascular diseases, such as hypertension, heart failure, among others (Hunyady and Catt, 2006). Marott et al. (2013) based on a genetic study with patients with AF, reported that I103T-A244S and A244S mutations in the AT1R were directly associated with the predisposition to the development of this condition in men. Indeed, the I103T and
A244S mutations (Figure 1A) are located respectively in the AT1R transmembranes helices 3 (TM3) and 6 (TM6), regions that have been described to bear critical residues that compose binding pockets for peptide and non-peptide ligands in different GPCRs (de Gasparo et al., 2000; Martin et al., 2004; Balakumar and Jagadeesh, 2014).

Thus, in the present study we aimed to evaluate whether the presence of the I103T-A244S and A244S would affect the downstream signaling of the AT1R, which in turn could have possible implications in AF. To allow a full structural/functional analysis, and as well to better understand why only A244S and the double mutation have been correlated with AF, we also generated and analyzed the I103T AT1R mutant. Our data show the decrease in $\beta$-arrestin recruitment by I103T-A244S mutant, which could be related to distinct conformations stabilized by the mutant receptorligand complex disfavoring arrestin coupling, since calcium mobilization was not affected in a large extent. Considering the impaired I103T-A244S mutant receptor interaction with $\beta$-arrestin, we inferred that this receptor should present a lesser extent of internalization. Based on that, a possible correlation with the clinical outcome is that the damaging effects of $G_{\alpha q}$ sustained activation, such as cardiomyocytes apoptosis, vasoconstriction and cardiac hypertrophy could be prolonged, impairing the AT1R receptor signaling and eventually contributing to $\mathrm{AF}$ development (Adams et al., 1998; Adams et al., 2000). Considering the impaired I103T-A244S mutant receptor interaction with $\beta$-arrestin, we inferred that this receptor should present a lesser extent of internalization. Based on that, a possible correlation with the clinical outcome is that the damaging effects of $\mathrm{G}_{\alpha \mathrm{q}}$ sustained activation, such as cardiomyocytes apoptosis, vasoconstriction and cardiac hypertrophy, could eventually favoring AF development (Adams et al., 1998; Adams et al., 2000). It is interesting to highlight that the receptor bearing only the I103T mutation shows an unaffected recruitment of $\beta$-arrestin as compared to the WT receptor.

Besides the activation of direct effectors (i.e. $\mathrm{G}$ protein and arrestins), AT1R signaling also promotes downstream phosphorylation of different kinases and substrates that are involved in alterations in extracellular matrix, gap junction formation, ion channels functionality, and others (DeWire et al., 2007; Shaul and Seger, 2007; Forrester et al., 2018). Mutations may change the conformation of a receptor. This change may induce different signaling responses after the activation with agonists or the inactivation with antagonists. The ligand's induced change in the mutant receptor's conformation may or may not favor its interaction with other signaling molecules (Wingler et al., 2019). Many of those signaling molecules are the kinases, which control a myriad of processes, such as apoptosis and cell proliferation, key events related to atrial remodeling, development and progression of AF (Zheng et al., 2014; Zheng et al., 2015; Nattel, 2017). In the current study, 18 kinases and kinases' substrates phosphorylation levels suffered modulation of at least $30 \%$ by at least one of the three mutant receptors, when comparted to WT AT1R. Interestingly, some of the identified kinase substrates have been described to be involved in physiological processes that are associated to the development of AF. 
ERK1/2, c-Jun and p70 S6 kinase, which have been related to the predisposition to cardiac injuries (for review, see Forrester et al., (2018)), had their phosphorylation levels increased by the A244S. In fact, studies show that ERK1/2, when upregulated, stimulates fibrotic tissue formation in heart. This condition contributes to cardiac hypertrophy and AF development (Shaul and Seger, 2007; Mebratu and Tesfaigzi, 2009; Wang et al., 2015). The I103T mutation is apparently the triggeringmechanism for increasing the receptor's ability to activate the ERK1/2. In the double mutant, the A244S mutation promotes the balance of this signaling, since it reduces the ability of the receptor to promote activation of ERK1/2, reaching levels that are closer to the WT receptor. The reduction of the phosphorylation level of CREB induced by the I103T-A244S mutant can also be associated to the AF phenotype, and the results indicate that the mutation responsible for this event is $\mathrm{I103T}$. As a previous study showed that a decreased expression of genes modulated by CREB are related to atrial remodeling, alterations in metabolism, impairment of the cardiac contractility function and regulation of the electric activity (Mayr and Montminy, 2001; Seidl et al., 2017). In addition to this, the elevation of eNOS phosphorylation levels indicates that the double mutant receptor may be involved in the predisposition to AF condition, as eNOS activation has a role in endothelial dysfunction and in the blood pressure increase (Daiber et al., 2019).

An important protein with a cardioprotective role is the HSP27 (Wu et al., 2015), which presented a specially lower activation for the I103T-A244S double mutant, indicating the possible contribution of such polymorphism to the progression of the disease. Glycogen synthase kinase-3 $\alpha / \beta($ GSK3 $\alpha / \beta)$ is another key protein that presented modulated phosphorylation levels in I103T-A244S transfected cells. It is described that the isoforms a and $\beta$ of GSK3 are active when dephosphorylated, acting against the growth of cardiac cells and protecting fibrosis tissue formation (Lal et al., 2015). Therefore, the decreased phosphorylation levels observed for GSK3 suggest an increased activity of both isoforms, which in turn, might be considered beneficial.

Besides the above-mentioned targets, which were modulated over threshold, a modest modulation was also observed for other substrates (Figure 2A). For example, WNK isoforms, Src and Srcrelated kinases, AMPK, GSK3/Akt pathway, among others, showed a different phosphorylation profile induced by the analyzed mutations, when compared to WT AT1R. All of them have been described to be involved on different cardiovascular dysfunctions, fibrosis and atrial fibrillation (Penela et al., 2001; Fessart et al., 2005; Kim et al., 2005; Gavi et al., 2006; Kraja et al., 2011; Harada et al., 2015; Qi et al., 2017; Van Gastel et al., 2018), thus these signaling pathways could also be contribute to the AF phenotype induced by the studied AT1 mutations.

Our results reveal that the AF-related AT1R mutants have their signaling profiles altered, as illustrated in Figure 2C. For instance, when stimulated with AngII the A244S mutant led to phosphorylation of kinases that are involved in aggravating AF. Also, our data suggest that the AF condition may be more critical in patients that carry the AT1R I103T-A244S variants, as recruitment of $\beta$-arrestin 2 was significantly reduced. Furthermore, kinase substrate profiling after activation of the double mutant receptor suggests that it can be related to higher predisposition of AF development.

Moreover, considering that the mutations led to a reduced receptor expression in relation to the WT receptor, the effects in the individuals bearing such mutations may be due to the expression per se, or also a consequence of the alteration in the receptor capacity to form homodimers and heterodimers, which may interfere in the AT1R signaling profile. It is also important to mention that the physiological impact of these mutations needs to be addressed in future studies using animal models of atrial fibrillation. Also, in the context of biased agonism of GPCR, which has been envisioned as a promise for better or more specific therapies, analysis of different AT1R ligands for treatment of AF shall also be studied.

\section{DATA AVAILABILITY STATEMENT}

The raw data supporting the conclusions of this article will be made available by the authors, without undue reservation.

\section{AUTHOR CONTRIBUTIONS}

SS conceived the research. SS and AS carried out the experiments and data analysis. $A B$ processed the experimental data of the phospho-kinase profiler array. SS and AS wrote the manuscript with support from LP-S, AB, CC-N, and MB. LP-S and CC-N supervised the project.

\section{FUNDING}

This research was supported by the Sao Paulo State Research Foundation (FAPESP), Grant 2012/20148-0 to CC-N, and by Grants from the Canadian Institute for Health Research to MB. $\mathrm{CC}-\mathrm{N}$ and $\mathrm{MB}$ had a joint international cooperation grant funded by FAPESP, Grant SPRINT 2015/50086-4. LP-S holds a Young Researcher grant from FAPESP (2016/24120-3). This study was financed in part by the Coordination for the Improvement of Higher Education Personnel (CAPES - Brazil) - Finance Code 001. SCS was recipient of a FAPESP fellowship (2016/08920-0). ALBS was recipient of a CAPES fellowship (88882.179973/2018-01).

\section{ACKNOWLEDGMENTS}

We thank Dra. Andrea Gutierrez Maria and Dr. Jhonatan Christian Maraschin for the valuable considerations about this manuscript.

\section{SUPPLEMENTARY MATERIAL}

The Supplementary Material for this article can be found online at: https://www.frontiersin.org/articles/10.3389/fphar.2020.600132/ full\#supplementary-material. 


\section{REFERENCES}

Adams, J. W., Pagel, A. L., Means, C. K., Oksenberg, D., Armstrong, R. C., and Brown, J. H. (2000). Cardiomyocyte apoptosis induced by Galphaq signaling is mediated by permeability transition pore formation and activation of the mitochondrial death pathway. Circ. Res. 87, 1180. doi:10.1161/01.RES.87.12. 1180

Adams, J. W., Sakata, Y., Davis, M. G., Sah, V. P., Wang, Y., Liggett, S. B., et al. (1998). Enhanced Galphaq signaling: a common pathway mediates cardiac hypertrophy and apoptotic heart failure. Proc. Natl. Acad. Sci. USA 95, 10140. doi:10.1073/pnas.95.17.10140

Balakumar, P., and Jagadeesh, G. (2014). Structural determinants for binding, activation, and functional selectivity of the angiotensin AT1 receptor. J. Mol. Endocrinol. 53, R71. doi:10.1530/JME-14-0125

Chang, H., Park, D., Wu, D., Goo Rhee, S., and Simon, M. I. (1992). Members of the Gq alpha subunit gene family activate phospholipase C beta isozymes. J. Biol. Chem. 267, 16044

Daiber, A., Xia, N., Steven, S., Oelze, M., Hanf, A., Kröller-Schön, S., et al. (2019). New therapeutic implications of endothelial nitric oxide synthase (eNOS) function/dysfunction in cardiovascular disease. Int. J. Mol. Sci. doi:10.3390/ ijms20010187

de Gasparo, M., Catt, K. J., Inagami, T., Wright, J. W., and Unger, T. (2000). International union of pharmacology. XXIII. The angiotensin II receptors. Pharmacol. Rev. 52, 415-472.

DeWire, S. M., Ahn, S., Lefkowitz, R. J., and Shenoy, S. K. (2007). Beta-arrestins and cell signaling. Аnnu. Rev. Physiol. 69, 483 doi:10.1146/annurev.physiol.69. 022405.154749

Fessart, D., Simaan, M., and Laporte, S. A. (2005). c-Src regulates clathrin adapter protein 2 interaction with beta-arrestin and the angiotensin II type 1 receptor during clathrin- mediated internalization. Mol. Endocrinol. 19, 491. doi:10. 1210/me.2004-0246

Forrester, S. J., Booz, G. W., Sigmund, C. D., Coffman, T. M., Kawai, T., Rizzo, V., et al. (2018). Angiotensin II signal transduction: an update on mechanisms of physiology and pathophysiology. Physiol. Rev. 98, 1627-1738. doi:10.1152/ physrev.00038.2017

Fukami, M., Suzuki, E., Igarashi, M., Miyado, M., and Ogata, T. (2018). Gain-offunction mutations in G-protein-coupled receptor genes associated with human endocrine disorders. Clin. Endocrinol. 88, 351-359. doi:10.1111/cen. 13496

Fyhrquist, F., and Saijonmaa, O. (2008). Renin-angiotensin system revisited. J. Intern. Med. 264, 224. doi:10.1111/j.1365-2796.2008.01981.x

Gavi, S., Shumay, E., Wang, H. Y., and Malbon, C. C. (2006). G-proteincoupled receptors and tyrosine kinases: crossroads in cell signaling and regulation. Trends Endocrinol. Metabol. 17, 48. doi:10.1016/j.tem.2006. 01.006

Harada, M., Tadevosyan, A., Qi, X., Xiao, J., Liu, T., Voigt, N., et al. (2015). Atrial fibrillation activates AMP-dependent protein kinase and its regulation of cellular calcium handling: potential role in metabolic adaptation and prevention of progression. J. Am. Coll. Cardiol. 66, 47. doi:10.1016/j.jacc. 2015.04.056

Hauser, A. S., Attwood, M. M., Rask-Andersen, M., Schiöth, H. B., and Gloriam, D. E. (2017). Trends in GPCR drug discovery: new agents, targets and indications. Nat. Rev. Drug Discov. 16, 829-842. doi:10.1038/ nrd.2017.178

Hunyady, L., and Catt, K. J. (2006). Pleiotropic AT1 receptor signaling pathways mediating physiological and pathogenic actions of angiotensin II. Mol. Endocrinol. 20, 953. doi:10.1210/me.2004-0536

Kim, N.-H., Ahn, Y., Oh, S. K., Cho, J. K., Park, H. W., Kim, Y.-S., et al. (2005). Altered patterns of gene expression in response to chronic atrial fibrillation. Int. Heart J. 46, 383-395. doi:10.1536/ihj.46.383

Kraja, A. T., Hunt, S. C., Rao, D. C., Dávila-Román, V. G., Arnett, D. K., and Province, M. A. (2011). Genetics of hypertension and cardiovascular disease and their interconnected pathways: lessons from large studies. Curr. Hypertens. Rep. 13, 46. doi:10.1007/s11906-010-0174-7

Lal, H., Ahmad, F., Woodgett, J., and Force, T. (2015). The GSK-3 family as therapeutic target for myocardial diseases. Circ. Res. 116, 138. doi:10.1161/ CIRCRESAHA.116.303613
Lima, V., Costa-Neto, C. M., Rodríguez, D. Y., Maria, A. G., Santos, G. A., Prando, É. C., et al. (2014). Non-canonical signalling and roles of the vasoactive peptides angiotensins and kinins. Clin. Sci. 126, 753. doi:10.1042/cs20130414

Marott, S. C. W., Nordestgaard, B. G., Jensen, G. B., Tybjærg-Hansen, A., and Benn, M. (2013). AT1 mutations and risk of atrial fibrillation based on genotypes from 71,000 individuals from the general population. Br. J. Clin. Pharmacol. 76, 114. doi:10.1111/bcp.12050

Martin, S. S., Boucard, A. A., Clément, M., Escher, E., Leduc, R., and Guillemette, G. (2004). Analysis of the third transmembrane domain of the human type 1 angiotensin II receptor by cysteine scanning mutagenesis. J. Biol. Chem. 279, 51415. doi:10.1074/jbc.M407965200

Mayr, B., and Montminy, M. (2001). Transcriptional regulation by the phosphorylation-dependent factor creb. Nat. Rev. Mol. Cell Biol. 2, 599. doi:10.1038/35085068

Mebratu, Y., and Tesfaigzi, Y. (2009). How ERK1/2 activation controls cell proliferation and cell death: is subcellular localization the answer?. Cell Cycle 8, 1168. doi:10.4161/cc.8.8.8147

Namkung, Y., LeGouill, C., Kumar, S., Cao, Y., Teixeira, L. B., Lukasheva, V., et al. (2018). Functional selectivity profiling of the angiotensin II type 1 receptor using pathway-wide BRET signaling sensors. Sci. Signal. 11, eaat1631. doi:10. 1126/scisignal.aat 1631

Nattel, S. (2017). Molecular and cellular mechanisms of atrial fibrosis in atrial fibrillation. JACC Clin. Electrophysiol. 3, 425-435. doi:10.1016/j.jacep.2017. 03.002

Parreiras-E-Silva, L. T., Vargas-Pinilla, P., Duarte, D. A., Longo, D., Espinoza Pardo, G. V., Finkler, A. D., et al. (2017). Functional New World monkey oxytocin forms elicit an altered signaling profile and promotes parental care in rats. Proc. Natl. Acad. Sci. USA 114, 9044. doi:10.1073/pnas. 1711687114

Penela, P., Elorza, A., Sarnago, S., and Mayor, F., J. (2001). Beta-arrestin- and c-Srcdependent degradation of G-protein-coupled receptor kinase 2. EMBO J. 20, 5129. doi:10.1093/emboj/20.18.5129

Qi, H., Liu, Y., Li, S., Chen, Y., Li, L., Cao, Y., et al. (2017). Activation of AMPK attenuated cardiac fibrosis by inhibiting CDK2 via p21/p27 and miR-29 family pathways in rats. Mol. Ther. Nucleic Acids 8, 277. doi:10.1016/j.omtn. 2017.07.004

Rask-Andersen, M., Sällman Almén, M., and Schiöth, H. B. (2011). Trends in the exploitation of novel drug targets. Nat. Rev. Drug Discov. 10, 579. doi:10.1038/ $\operatorname{nrd} 3478$

Santos, G. A., Duarte, D. A., Parreiras-e-Silva, L. T., Teixeira, F. R., Silva-Rocha, R, Oliveira, E. B., et al. (2015). Comparative analyses of downstream signal transduction targets modulated after activation of the AT1 receptor by two $\beta$-arrestin-biased agonists. Front. Pharmacol. 6, 131. doi:10.3389/fphar.2015. 00131

Schöneberg, T., Schulz, A., Biebermann, H., Hermsdorf, T., Römpler, H., and Sangkuhl, K. (2004). Mutant G-protein-coupled receptors as a cause of human diseases. Pharmacol. Ther. 104, 173. doi:10.1016/j.pharmthera. 2004.08.008

Seidl, M. D., Stein, J., Hamer, S., Pluteanu, F., Scholz, B., Wardelmann, E., et al. (2017). Characterization of the genetic program linked to the development of atrial fibrillation in CREM-Ib $\Delta$ C-X mice. Circ Arrhythm Electrophysiol. 10 (8). doi:10.1161/CIRCEP.117.005075

Shaul, Y. D., and Seger, R. (2007). The MEK/ERK cascade: from signaling specificity to diverse functions. Biochim. Biophys. Acta 1773, 1213. doi:10. 1016/j.bbamcr.2006.10.005

Van Gastel, J., Hendrickx, J. O., Leysen, H., Santos-Otte, P., Luttrell, L. M., Martin, B., et al. (2018). $\beta$-Arrestin based receptor signaling paradigms: potential therapeutic targets for complex age-related disorders. Front. Pharmacol. 9, 1369. doi:10.3389/fphar.2018.01369

Wang, W., Zhang, F., Chen, J., Chen, X., Fu, F., Tang, M., et al. (2015). Telmisartan reduces atrial arrhythmia susceptibility through the regulation of RAS-ERK and PI3K-Akt-eNOS pathways in spontaneously hypertensive rats. Can. J. Physiol. Pharmacol. 93, 657. doi:10.1139/cjpp2014-0416

Wingler, L. M., McMahon, C., Staus, D. P., Lefkowitz, R. J., and Kruse, A. C. (2019). Distinctive activation mechanism for angiotensin receptor revealed by a synthetic nanobody. Cell 176, 479-490.e12. doi:10.1016/j.cell.2018.12. 006 
Wise, A., Jupe, S. C., and Rees, S. (2004). The identification OF ligands at orphan g-protein coupled receptors. Annu. Rev. Pharmacol. Toxicol. 44, 43. doi:10. 1146/annurev.pharmtox.44.101802.121419

Wu, D., Katz, A., Lee, C. H., and Simon, M. I. (1992). Activation of phospholipase C by alpha 1-adrenergic receptors is mediated by the alpha subunits of Gq family. J. Biol. Chem. 267, 25798.

Wu, W., Lu, Z., Li, Y., Chen, Z., Jiang, H., and Li, Y. (2015). Decreased cardiac expression of heat shock protein 27 is associated with atrial fibrillation in patients with rheumatic heart disease. Acta Cardiol. Sin. 31, 1. doi:10.6515/ACS20140526A

Zalewska, M., Siara, M., and Sajewicz, W. (2014). G protein-coupled receptors: abnormalities in signal transmission, disease states and pharmacotherapy. Acta Pol. Pharm. 71, 229-243.

Zheng, L., Jia, X., Zhang, C., Wang, D., Cao, Z., Wang, J., et al. (2015). Angiotensin ii in atrial structural remodeling: the role of ang II/JAK/STAT3 signaling pathway. Am. J. Transl. Res. 7, 1021.
Zheng, L. Y., Zhang, M. H., Xue, J. H., Li, Y., Nan, Y., Li, M. J., et al. (2014). Effect of Angiotensin II on STAT3 mediated atrial structural remodeling. Eur. Rev. Med. Pharmacol. Sci. 18, 2365.

Conflict of Interest: The authors declare that the research was conducted in the absence of any commercial or financial relationships that could be construed as a potential conflict of interest.

Copyright (c) 2020 Simões, Balico-Silva, Parreiras-e-Silva, Bitencourt, Bouvier and Costa-Neto. This is an open-access article distributed under the terms of the Creative Commons Attribution License (CC BY). The use, distribution or reproduction in other forums is permitted, provided the original author(s) and the copyright owner(s) are credited and that the original publication in this journal is cited, in accordance with accepted academic practice. No use, distribution or reproduction is permitted which does not comply with these terms. 